\title{
—拳 \\ O PATRIMÔNIO INDUSTRIAL COMO ELEMENTO DA PAISAGEM CULTURAL E A PAISAGEM CULTURAL CONFORMANDO O PATRIMÔNIO INDUSTRIAL: UMA RELAÇÃO CONCEITUAL
}

\section{- ZANDOR GOMES MESQUITA*}

Resumo: O Patrimônio Industrial diz respeito aos resquícios do modo de produzir de uma sociedade, constituídos de seu valor histórico, tecnológico, social e arquitetônico ou científico. Ele vai além do seu aspecto estético, ressaltado pelo visível. Sua análise possibilita uma conexão com o tipo de industrialização de um período histórico, com o modo de vida da classe trabalhadora correspondente, evidencia também a coletividade que o construiu e permite entender os processos de conformação do espaço na qual essa população residia. Neste sentido, o patrimônio industrial está intimamente relacionado a paisagem cultural. Esta pode ser entendida como um produto da apropriação e transformação do homem sobre a natureza, constituindo um conjunto de significados, impressos através da linguagem, dos símbolos e traços culturais do grupo social em questão. Dotada de sentido e ancorada sobre uma base material, a paisagem se apresenta como uma importante fonte investigativa, sendo vista como uma expressão concentrada da identidade coletiva. 0 seu estudo expõe as dinâmicas sociais que se estabeleceram sobre o espaço, que foram caracterizadas a partir das relações que ali se desenvolveram, sendo então, um importante documento de análise. Neste sentido, estes dois conceitos interagem e a utilização em conjunto possibilita o desenvolvimento de um campo de análise. 0 patrimônio industrial influencia na conformação da paisagem cultural, lhe dá vida, altera suas características, e também é composto por ela, sendo influenciado pela sua estruturação. 0 presente trabalho buscou debater a relação destes dois conceitos, expondo elementos para o estabelecimento de um debate.

Palavras-chave: Patrimônio Industrial; Paisagem Cultural; Geografia Cultural; Ciências Sociais. 
Introdução

0 presente trabalho discute as relações existentes entre os conceitos de paisagem cultural e 0 de patrimônio industrial. T rabal ha-se com a ideia de que o patrimônio industrial é um elemento integrante da paisagem cultural, influenciando a sua conformação. Ao mesmo tempo, a paisagem interfere na dinâmica de constituição do patrimônio industrial, expondo elementos que influenciam a sua caracterização.

As discussões acerca da conceituação de paisagem cultural encontram-se em destaque atualmente, através de conferências e trabalhos real izados pela U NESCO e pela Convenção Europeia de Paisagem. De maneira geral, pode-se definir paisagem cultural como 0 meio natural ao qual o ser humano, em sua vivência, deixou registro de suas ações, sua forma de agir e se expressar. Por seu intermédio, se faz possível remontar passados longínquos, tornando sua preservação e estudo necessário. Nesta situação, a paisagem cultural ganha status de patrimônio, tendo a necessidade de elaboração de ações específicas que visem sua salvaguarda.

No que tange ao patrimônio industrial, o desenvolvimento do seu conceito se deu principalmente na Europa pós Segunda Guerra Mundial. Com a destruição que este evento ocasionou, ressaltou-se a necessidade de proteção desse bem. Seu estudo vai além das grandes estruturas arquitetônicas, com expressivo valor estético, ele representa a cultura de um povo, enfatizando o modo de produzir e a sociabilidade que dele deriva. Cabe destacar que os estudos do patrimônio industrial não estão restritos ao período pós Revolução Industrial. Entende-se que os processos produtivos anteriores a essa fase possuem elementos que podem ser considerados industriais (como a divisão do trabalho, utilização de ferramentas, uso de fontes de energia, etc.), logo, não podem ficar à margem do debate.

Com estas perspectivas expostas, 0 artigo debaterá os principais aspectos que norteiam esses conceitos, expondo suas principais características, estruturando sua definição, implementando as bases para a sua relação, enfatizando a importância da mesma para possíveis discussões futuras.

Patrimônio: um conceito em construção

0 trato do patrimônio nos remete a herança acumulada ao longo dos anos, tanto por indivíduos quanto por grupos, que reconhecem num determinado bem singularidades especiais, seja de valor econômico, afetivo ou simbólico. Se tidos como uma representação da coletividade são tratados como uma resultante e um 
significante do processo cultural. Assim, conceder a algo 0 status de patrimônio é enfatizar a característica peculiar de um grupo, ressaltando-a como uma representação de sua dinâmica.

A etimologia do patrimônio está relacionada, originalmente, a herança paterna, ou seja, aos bens materiais transmitidos de pai para filho. Proveniente do latim patrimonium, derivada de pater (pai) o termo guarda em si a ideia de propriedade, que no caso específico, diz respeito aos pertences de uma nação (CHAUí, 1992). Enquanto conceito, diversas foram as acepções construídas, variando de acordo com o contexto inserido. Sob a forma de herança social o termo aparece na França pósRevolucionária, com os intelectuais imbuídos nos ideais iluministas, que atribuíram ao Estado o papel de tutelar e proteger os resquícios que representavam a história da nação (FUNARI e PELEGRINI， 2009; TEIXEIRA，2006). Fez-se então a noção de que o patrimônio é de todos e como tal deve ser preservado para que as características de um povo sejam protegidas, cabendo ao Estado 0 estabelecimento dos seus limites físicos e conceituais (F ON SE CA, 2005).

Cabe ressaltar que a realização desta tarefa, ao longo da história, gerou exclusões, já que ao definir um patrimônio, com determinadas características, como nacional, outros ficavam as margens, tendo seus referenciais sobrepostos em função de algo comum a todos. Dessa maneira o processo de "patrimonialização" torna-se uma ação política, pois a escolha e classificação dos bens que deveriam servir para representar toda nação, passam a ser utilizado pelo Estado como uma ferramenta de afirmação e reafirmação de suas ações (FONSECA, 2005). Assim, o patrimônio se torna uma construção subjetiva, variando de acordo com o contexto, mudando de significado na medida em que diferentes valores forem acrescidos ao seu entendimento. Sobre este ponto Fonseca ressalta (2005):

Se os valores que se pretende preservar são apreendidos na coisa e somente nela, não se pode deixar de levar em consideração o fato obvio de que os significados nela não estão contidos, nem Ihe são inerentes: são valores atribuídos em função de determinadas relações entre atores sociais, sendo, portanto, indispensável levar em consideração o processo de produção, de reprodução, de apropriação e de re-elaboração desses valores enquanto processo de produção simbólica e enquanto prática social (2005; p.41).

Atualmente novas variáveis são introduzidas no entendimento de um bem 
enquanto patrimônio. Por este motivo, seu sentido é ampliado, deixando de ser apenas - que se herda, mas também o que constitui e influencia a consciência de um grupo, sendo campo de negociações, disputas, etc. Este processo ocorre atrelado ao processo de globalização (responsável pela mudança no ritmo das transformações sociais, as intensificando), fazendo com que, segundo Santos (2001), seja necessária a tutela dos bens culturais de um povo, a fim de manter ressaltada sua identidade, evitando a supressão, dissipando a geração antecedente. Além disso, neste novo contexto, (consolidação do processo de globalização - entendida não apenas como a mundialização do capital, mas sim como um processo que possibilita um maior contato entre diferentes comunidades, tornando as fronteiras tradicionais mais porosas) assuntos nacionais tendem a se tornar causas comuns da humanidade. Assim, a homogeneização e uniformização dos aspectos culturais tornam-se um risco cada vez mais presente na medida em que 0 contato é intensificado e acelerado, possibilitando a imposição de modelos por parte dos centros criadores de consumo e detentores do poder (SANT OS, 2001).

Por outro lado, a particularização das culturas (tida como uma estratégia de fuga da homogeneização) também ganha um novo contorno no contexto da globalização. Neste âmbito têm-se ressaltado a singularidade, a autenticidade e a particularidade do patrimônio. Essa estratégia faz com que as culturas se fechem, gerando um movimento de intensificação dos processos de resistências. Assim, o glocalismo se faz presente e busca nas características do local uma forma de resistir ao contexto.

Contudo, até mesmo a particularização do patrimônio, na nova fase de globalização, adquire função de mercadoria, podendo ser empacotado, fabricado e distribuído para ser consumido (CHOAY, 2003). Com isso, como afirma Harvey (2005), a cultura é transformada em commodities, onde o capital absorve as tradições locais e as inovações culturais, transformando-as em renda, gerando lucro. Para Chauí (1992) essa característica fica evidente quando se percebe a disparidade existente entre a preservação dos bens móveis e imóveis. Para essa autora, ao se proteger objetos de arte, coleções de documentos privados, fotografias, mobiliário, etc. há uma contribuição para a valorização das mesmas perante as leis do mercado, devido à significância que Ihe é atribuída, ganhando 0 status de antiguidades. Porém, quando se aplica a legislação aos bens imóveis há uma desvalorização das mesmas. Essa situação explicita o controle da classe dominante sobre 0 critério e as práticas de preservação, sendo materializada pelo 
cultivo do consumo sofisticado.

No Brasil, a visão elitista sobre 0 patrimônio se faz presente desde a constituição das políticas de preservação. Criado como secretaria durante o G overno Vargas, 0 Instituto do Patrimônio Histórico Artístico Nacional (IPHAN) é 0 órgão federal responsável pelo trato do patrimônio em nosso país. Em sua gênese tinha por finalidade a salvaguarda dos bens edificados de caráter histórico e artístico que representavam a nação. N um primeiro momento, este órgão, baseado nas ideias de um determinado grupo de especialistas, preconizou a proteção dos remanescentes da arte colonial brasileira, afirmando que estas corriam riscos por conta do processo de urbanização que se acelerava, dos saques e comercialização indevidos dos bens móveis. Neste período, suas ações foram desenvolvidas visando à salvaguarda dos bens do século XVI, XVII e XVIII, ressaltando a arquitetura religiosa. Tal situação representava 0 interesse das classes mais altas, já que as mesmas consideravam que o modelo de civilização a ser seguido estava contido nos países desenvolvidos estrangeiros e que a única maneira de o Brasil crescer era copiando esses tipos externos (F ON SECA, 2005).

Assim, percebe-se que a constituição do patrimônio brasileiro é fruto de um jogo político, com ações que preconizavam a ideia de um grupo específico, que consolidaram, nesse primeiro momento, uma perspectiva predominantemente estética, não tendo a preocupação de incorporação da história nacional nos seus estudos (tanto que no SPHAN não havia historiador no seu quadro de funcionários). $\mathrm{Na}$ década de 1960 esse quadro ganha novos contornos. Isto ocorre devido aos movimentos entorno da cultura popular, como resistência a ditadura, levado adiante pelos estudantes e operários e pelos avanços dos anos 70 em outras partes do mundo, sobretudo na Europa. Essa nova situação influencia a criação do Centro $\mathrm{N}$ acional de Referência Cultural - CNRC, que procurou ampliar 0 debate crítico acerca do patrimônio cultural a esfera conceitual. Neste âmbito o CNRC voltou sua atenção para 0 tratamento da cultura viva, dando ênfase ao saber popular, tentando tornar mais nacional à cultura brasileira. Porém, ainda persistia a ideia que era de responsabilidade dos intelectuais a produção do conhecimento e valorização da cultura (F ON SE CA, 2005).

A partir da década de 1980 há uma mudança no tratamento da política cultural no Brasil. Com destaque para a atuação de Aloísio M agalhães, os debates acerca das políticas culturais de preservação nacional ganham novos contornos, com a inserção da população nas discussões, entendendo que este não pode ser visto como um 
simples objeto de estudo, mas sim como co-autor do processo. Neste contexto, há uma mudança de perspectiva do patrimônio cultural brasileiro possibilitando a inserção de novos grupos até então marginalizados (Indígenas, negros, populações rurais, etc.). Essa nova perspectiva que norteia 0 patrimônio cultural nacional é refletida na Constituição de 1988. Isso fica claro no artigo 215 quando registra-se que:

(...) O Estado garantirá a todos 0 pleno exercício dos direitos culturais e acesso às fontes da cultura nacional, e apoiará e incentivará a valorização e a difusão das manifestações culturais; protegendo as manifestações das culturas populares, indígenas eafro-

brasileiras, e das de outros grupos participantes do processo civilizatório nacional (BRASIL, 1988; art. 215).

Nesse documento têm-se também uma ampliação do / conceito de patrimônio cultural, onde o mesmo passa a ser definido como: (...) os bens de natureza material e imaterial, tomados individualmente ou em conjunto, portadores de referência à identidade, à ação, à memória dos diferentes grupos formadores da sociedade brasileira (BRASIL, 1988: art. 216). Assim abre-se espaço para a valorização da cultura popular, com suas práticas, crenças e valores simbólicos, conferindo importância a novos grupos sociais, possibilitando assim o exercício da cidadania (F ON SE CA, 2005).

Quando trabalha-se com 0 Patrimônio Cultural aborda-se bens com diferentes características. De maneira geral pode-se dividi-lo em material e imaterial, levando em consideração as características intrínsecas do bem. M as também, podem ser agrupados nas categorias: Arquitetônico (e/ ou Edificado), Natural (e/ ou A mbiental), A rqueológico, Artístico e Religioso. Cabe ressaltar que esta classificação não é definitiva, podendo ser alterada de acordo com o ponto de vista utilizado ou de acordo com a especificidade do patrimônio em questão. N esta divisão, aparece o Patrimônio Industrial, uma forma de patrimonialização que vai muito além do processo produtivo a partir de um período específico e que merece ser ressaltado.

0 patrimônio industrial: 0 desenvolvimento do conceito

Ao se definir 0 patrimônio industrial deve-se levar em consideração que 0 mesmo não trata apenas de grandes estruturas, com grande valor arquitetônico, máquinas antigas ou espaços ociosos que foram engolidos pela 
modernidade, onde se dava 0 funcionamento de determinada produção. Seu conceito vai além, sendo parte constituinte da vida de homens e mulheres comuns, que Ihe confere valor identitário e, através de seus estudos, faz-se possível compreender o tipo de industrialização (e tecnologia) de uma época, assim como o modo de vida da classe trabalhadora correspondente. Os vestígios materiais das atividades produtivas tais como, fábricas antigas, ferramentas e edificações que as abrigam, têm uma excepcional importância não só para 0 arquiteto, construtor e engenheiro, mas também para 0 historiador, sociólogo, arqueólogo, ou seja, todos os estudiosos que tenham 0 desenvolvimento da sociedade como foco de pesquisa, pois através destes testemunhos materiais se faz possível compreender as transformações ocorridas em uma sociedade e a maneira pela qual estas se deram.

Assim, o estudo do patrimônio industrial refuta uma leitura exclusiva do local de produção enquanto edifício, limitado aos aspectos particulares, tecnológicos e artísticos, excluída de uma complexa rede coordenadora que o define historicamente. Este objeto se apresenta segundo uma série de níveis de leitura, de aspectos ou de linguagens, todos intimamente relacionados, indispensável para 0 entendimento do espaço material no qual se desenvolveu uma dada sociedade industrial.

$\mathrm{U} \mathrm{m}$ ponto interessante que merece destaque acerca do patrimônio industrial está relacionado a subjetividade que 0 envolve e pela característica que apresenta, fazendo com que, por vezes, seja considerado um "patrimônio controverso" (MENDES, 2006). Esta situação deriva de vários fatores, dentre os quais, pode-se destacar: a sua associação ao trabalho e a produção industrial, que Ihe dá um aspecto pragmático; além de ter contra si o fato de não estar, de maneira geral, ligado a eventos de índole político-militar e religiosa que, até recentemente, constituía o principal foco de estudo da Academia; e também pelo componente estético que destoa dos gostos mais em voga entre os elementos dos grupos sociais dominantes.

Dessa maneira, Mendes (2006) afirma que a proteção ou reutilização do patrimônio industrial deve alicerçar-se, principalmente, no seu o valor artístico, 0 valor de uso e o valor histórico. No primeiro caso, 0 aspecto a ser ressaltado é a evolução da arquitetura industrial, remetendo aos períodos das antigas oficinas e manufaturas, trazendo até os dias atuais, enfatizando os detalhes das pequenas construções, feita inteiramente por processos manuais, que era comum no período que antecedeu a Revolução Industrial. 
No que tange ao valor de uso, há de se levar em consideração às necessidades da comunidade e, simultaneamente, procurando seu envolvimento e colaboração nos projetos de preservação e requal ificação. Sobre essa situação $M$ endes ressalta que não há soluções uniformes ou pré-estabelecidas para o problema, pois dependerá do respectivo meio, suas necessidades e condições (MENDES, 2006).

$M$ as 0 que mais chama a atenção e 0 que diz respeito ao valor histórico. Este leva em conta que determinada instalação industrial, além de ser considerada um monumento, é simultaneamente um documento, que se torna relevante não apenas pelo seu aspecto exterior, mas também por ser o lócus de uma série de relações entre 0 ambiente físico e humano, continuamente transformado pelo desenvolvimento industrial. Assim, independentemente do seu valor estético, as estruturas industriais podem nos transmitir informações diversas, de grande valia para o entendimento das relações da fábrica com o seu entorno. Como exemplo temos as chaminés, que são destacadas na paisagem, constituindo um símbolo característico da industrial ização, capaz de elucidar aspectos sobre 0 processo de transição da oficina em fábrica, servindo de símbolo de prosperidade e relacionado também a aspectos negativos, como a poluição.

Dessa maneira, como aponta M endes (2006), ao conceituar o patrimônio industrial, ressalta que o mesmo vale essencialmente pelo meio em que se insere, pela paisagem em que se revela como ícone, pelas relações que estabelece com 0 espaço e as memórias na diversidade de referências. E esta característica tem relação direta com os debates que cercam 0 conceitual de paisagem, assim, cabe uma melhor elucidação acerca deste conceito.

\section{A paisagem cultural: um conceito em construção}

Ao trabalhar com o conceito de paisagem faz-se necessário sua delimitação, dada a abrangência do termo e as diferentes acepções disciplinares a ele relacionadas, oscilando de acordo com 0 interesse do objeto e da forma com a qual será trabalhado. Silvestre (2009), exemplificando essa característica, aponta algumas maneiras pela qual o termo é trabalhado. Para este autor, a paisagem pode ser tida como uma representação (assim fazem os historiadores de cultura, humanistas, etc.); ou então como um espaço social e humanizado (esta via é explorada principalmente pelos geógrafos culturais); ou como o resultado da experiência vivida (como os filósofos fenomenológicos); ou a partir de uma perspectiva ativa, criativa e 
projectual, (assim como os paisagistas, arquitetos, etc.); ou utilizando como ponto de partida uma perspectiva naturalista, tendo-a como uma entidade objetiva (desta maneira trabalham os geólogos, climatólogos, ecologistas, etc.); Ou seja, inúmeros são os significados atribuídos a ela e isso deriva do fato dela ser composta não só por aquilo que está à frente de nossos olhos, mas sim, por aquilo que está contido em nossas mentes (MEINIG, 2002).

A multiplicidade de significados da paisagem também pode ser explicitada historicamente. Segundo Holzer (1999) o termo surge no século $X V$, derivando de landschaft (palavra de origem alemã que se refere a uma associação entre 0 sítio e seus habitantes), que por sua vez, deu origem ao termo holandês landschap (landskip), que, em outro momento, fez surgir à palavra landscape na língua inglesa. 0 termo holandês, apesar de seu significado ser igual ao correlato alemão, num primeiro momento, esteve associado às pinturas de paisagens naturais, percebida a partir de um determinado enquadramento, relacionando a paisagem a aquilo que se via através das janelas (CAST RO, 2005). Já 0 termo em inglês é comumente definido como uma extensão de um cenário natural, percebido pelos olhos em uma só visão. Com isso, percebe-se que, em sua gênese a paisagem esteve diretamente ligado ao estético e perceptível. $\mathrm{Na}$ língua portuguesa o termo deriva de paysage, palavra francesa cujo significado está atrelado às técnicas renascentistas, tendo como origem o radical medieval pays, que significa, ao mesmo tempo, habitante e território (HOLZER, 1999; CLAVAL,1999).

Diversos foram os sentidos atribuídos e várias foram às disciplinas que se dedicaram ao estudo da paisagem, porém, para a geografia ela é um conceitochave, pois serviu para 0 seu desenvolvimento, criando bases para sua consolidação enquanto ciência (HOLZER, 1999; CLAVAL, 2004). Os primeiros a avançarem nesse processo foram os geógrafos franceses e alemães, no século $X I X$, ao destituírem o sentido puramente romântico do conceito. Neste momento, a paisagem além de estética passa a ter um aspecto conceitual passível de reflexão e estudo empírico.

$\mathrm{Na}$ geografia alemã os primeiros autores em destaque foram Alexander Von Humboldt (Cosmos), Carl Ritter (G eografia Comparada) e Friedrich Ratzel (Antropogeografia). Humboldt ganha notoriedade pela visão holística que atribui à paisagem, trabalhando os elementos (naturais e humanos) que a constitui como um todo, sistematizando-os e transformando-a assim, em parte de uma atividade cientifica. Ritter, mesmo não se 
dedicando diretamente a temática, contribui de maneira significativa para 0 seu desenvolvimento, na medida em que dá prosseguimento a metodologia proposta por Humboldt, sistematizando os el ementos que compõe o local, organizando seus dados naturais e históricos, criando e consolidando uma ciência de caráter enciclopedista. M as foi com Ratzel que os estudos relativos à paisagem ganharam notoriedade, na medida em que introduz uma visão antropocêntrica ao conceito, apontando que a mesma é o resultado do distanciamento ocorrido entre as ações humanas e o meio natural.

M esmo com esses avanços, foi somente com a escola francesa que 0 conceito de paisagem passou a ser estruturado. N este contexto destacam-se os escritos de Paul Vidal de La Blache. Para este autor, a paisagem deve ser tratada como um todo, onde seus elementos constituintes se encadeiam e se coordenam (LA BLACHE, 1954). Assim, cada gênero de vida que a integra possui influencia na sua formação, se adequando ao meio presente, formando uma paisagemtipo. Desta maneira, grupos sociais com diferentes características cristalizam distintas formas na paisagem, transformando-a num objeto de investigação. $N$ as palavras do autor:

Por suas obras e pela influência que exerce sobre ele mesmo e 0 mundo vivente, 0 homem é parte integrante da paisagem. Ele a humaniza e a modifica de alguma forma. Por isso, o estudo de seus estabelecimentos fixos é particularmente sugestivo, visto que é de acordo com eles que se ordenam culturas, jardins, vias de comunicação; eles são os pontos de apoio das modificações que 0 homem produz sobre a terra. (...) eles representam um depósito que as gerações anteriores deixam às seguintes, um fundo de valor que dispensa começar (do zero) tudo de novo (VIDAL DE LA BLACHE, 1954; p. 150).

No início do século $X X$, as discussões acerca da influência direta do homem no ambiente aumentam, efeito direto da consolidação da Revolução Industrial e das transformações que esta propiciava por todo o mundo. Neste contexto, a ação humana é ressaltada, tida como um fato geográfico em si. Tal fato preteriu o conceito de paisagem, em função de outros como espaço, região, território e lugar (CORRÊA e ROSENDHAL, 1998). Porém, na segunda metade do século $X X$ conceito ganha força novamente, graças aos estudos da fenomenologia e da geografia cultural, quando passou a aceitar-se que o ser humano e o meio 
ambiente não podem ser reconhecidos como elementos distintos e autônomos (T OGASHI, 2009).

Sendo assim, gradativamente, os estudos das paisagens deixam de se preocupar exclusivamente com as estruturas que compõe a superfície da Terra e incorporam a questão humana como elemento modificador do ambiente, tornando a paisagem cultural predominante sobre a natural, mas sem perder de vista as interações mútuas, pois o ponto de partida é o visual, ou seja, a observação objetiva. Assim, a paisagem cultural vai ganhando destaque. No mundo em transformação, onde os objetos e artefatos tomam o lugar do natural (SANT OS, 1997).

Desta forma o meio natural vai cedendo espaço ao meio técnico (que se transforma em científico e informacional); 0 artificial predomina, preterindo 0 natural. I sso reflete tanto na constituição quanto no entendimento da paisagem, na medida em que sua interpretação leva em conta a modificação dos sentidos de quem a vislumbra. N este novo contexto, o homem, com suas intervenções, seja intencional ou não, é um elemento fundamental na análise da configuração das diferentes paisagens. I sso porque cada sociedade tem sua maneira peculiar de viver, têm sua própria organização social, de produção, características que, de certa maneira, são plasmadas no local de vivência.

Assim, da mesma maneira que ocorre nos estudos do patrimônio industrial, a paisagem assume papel de documento, representando características da sociedade que Ihe dá vida. Sobre este conceito, apesar de abordagens distintas, os estudos de Sauer, Cosgrove e Berque merecem destaque.

Sauer (1998) faz da paisagem um elemento balizador e afirma que seus estudos devem buscar uma identidade baseada na constituição do reconhecível, enfatizando seu aspecto passível de taxação e classificação, pois se apresenta como um organismo complexo, resultado das associações que podem ser analisadas. $\mathrm{Ou}$ seja, a paisagem possui forma, estrutura, funcionamento e posição, sendo incluso num sistema, que está sujeito a desenvolvimento, transformação e aperfeiçoamento. Para este autor, a paisagem pode ser considerada uma generalização oriunda da observação de cenas individuais, estando a cargo do estudioso de geografia sua descrição, de maneira excepcional, seja como um tipo ou uma variante de um tipo, porém, sempre tendo por necessidade sua comparação. E m suas palavras:

[A Paisagem] pode ser definida, por tanto, como uma área composta por uma associação de diferentes formas, tanto físicas 
como culturais. (...) A paisagem possui identidade que se sustenta na constituição do reconhecível, nos limites e na relação com outras paisagens, constituindo um sistema geral. Sua estrutura e função estão determinadas por formas integradas edependentes (SAUER, 1998; p. 95).

Assim, a paisagem geográfica passa a ser considerada um conjunto de formas, naturais e culturais, interligadas a uma área, que deve ser analisada morfologicamente, levando em consideração o grau de integração entre as diferentes formas. Por esta perspectiva, têm-se a separação da paisagem em dois tipos: as naturais (virgens), teoricamente intocadas ou sem significativos reflexos da ação antrópica; e as culturais, que são caracterizadas por possuírem traços característicos da ação humana, agindo como um agente da paisagem natural, que por sua vez passa a ser o resultado da ação cultural do grupo, acarretando transformações em função do uso de técnicas e instrumentos.

Diversas foram as críticas feitas a Sauer, tendo como base, principalmente, 0 aspecto positivista que permeou seu trabalho. Contudo, há um reconhecimento nas contribuições que ele traz para 0 debate. Tal aspecto é redesenhado e redefinido a partir das discussões da N ova Geografia Cultural. Segundo Corrêa (1997), esta não se apresenta em contraposição as noções sauerianas, mas sim como um complemento, ampliando suas bases epistemológicas, introduzindo uma matriz não positivista ao debate. Neste contexto, a paisagem passa a ser revestida de novos conteúdos, fruto da incorporação de noções como percepção, representação, imaginário e simbolismo ao seu conceito (CAST RO, 2005). Assim, ela deixa de levar em consideração unicamente seu aspecto morfológico e passa a ter ressaltado sua simbologia e redes de significância, possibilitando a adição de novas perspectivas (HOLZER, 1999; CORRÊA, 1997).

Nesse contexto, o conceito passa ter ressaltado o seu aspecto simbólico, impregnado de significados, que são passíveis de diferentes interpretações, sendo analisado a partir de diversas opções, pelos variados métodos de abordagem, pela natureza de sua teoria e interpretação, cujo objetivo comum é a elucidação das relações culturais presentes na sua configuração (CAST RO, 2005).

$E$ é neste processo que se destacam os escritos de Denis Cosgrove e Augustin Berque. 0 primeiro afirma que os estudiosos da geografia estão agindo de maneira incorreta nas análises das paisagens, pois estão despindo-se de suas 
paixões e, com isso, deixando de lado significados importantes que possam nelas estar contidos. Dessa maneira, há a necessidade de uma análise mais humana, utilizando-se de algumas habilidades interpretativas provenientes dos romances, do poema, do filme, do quadro, tratando-a como uma expressão humana intencional, composta de várias camadas de significados. Em suas palavras:

(...) as paixões incovenientemente, às vezes assustadoramente poderosas, motivadoras da ação humana, entre elas as morais, patrióticas, religiosas, sexuais e políticas. Todos sabemos quão fundamentalmente estas motivações influenciam nosso comportamento diário. (...). Contudo, na geografia humana parecemos intencionalmente ignorá-las ou negá-las. Consequentemente, nossa geografia deixa escapar muito do significado contido na paisagem humana, tendendo a reduzi-la a uma impressão impessoal de forças demográficas e econômicas (COSGROVE ; 1998; p. 97).

Nesta perspectiva a paisagem apresenta-se como um texto, dada sua condição de ser, ao mesmo tempo, produzido, contemplado, interpretado e por vezes consumido. Essa interpretação revela as relações de poder existente, pois sua caracterização pode se converter num discurso ideológico, assim como sua reprodutibilidade nas mais diversas mídias, fazendo com que o maior número de pessoas seja atingidas pelo discurso pretendido (NAM E, 2010). Assim, ela pode ser caracterizada como um produto da apropriação e transformação do homem sobre a natureza, constituindo um conjunto de significados impressos através da linguagem, dos símbolos e traços culturais do grupo social em questão.

Para Cosgrove (1998), os distintos tipos de apropriação e visão da paisagem relacionam-se, principalmente, com a questão do poder, revelando relações de dominação e opressão, neste processo. Segundo 0 autor:

Um grupo dominante procurará impor sua própria experiência de mundo, suas próprias suposições tomadas como verdadeiras, como a objetiva e válida cultura para todas as pessoas. 0 poder é expresso e mantido na reprodução da cultura. Isto é melhor concretizado quando menos visível, quando as suposições culturais do grupo dominante aparecem simplesmente como senso comum. Isto é as vezes chamado de hegemonia 
cultural. Há, portanto, culturas dominantes e subdominantes ou alternativas, não apenas no sentido político, mas também em termos de sexo, idade e etnicidade (COSGROVE; 1998; p.p. 104-105).

Neste sentido, o simbolismo da paisagem reproduz normas culturais vigentes, sendo preconizado os valores de grupos dominantes, que são os que detêm o poder. Porém, não somente este grupo compõe a paisagem. Sobre a mesma também exerce influência 0 grupo subdominante (alternativo), que molda 0 local de sociabilidade influenciado pela sua cultura e pela relação de dominação existente. Assim, a paisagem passa a ser plasmadas pela relação de diferentes grupos que a influenciam. Então, pode-se, a partir da leitura de Cosgrove, caracterizar dois tipos de paisagens que, apesar de distintos, são complementares entre si: 0 da cultura dominante (que revela os meios pelos quais seu poder é exercido) e o das paisagens alternativas (criadas por grupos não dominantes e que, por isso, apresenta menor visibilidade). Como fruto da relação entre essas duas paisagens têm-se a paisagem residual. Esta pode ser considerada um híbrido destas duas, pois é composta de elementos da paisagem dominante e subdominante. A paisagem residual é caracterizada por permitir uma análise e reconstrução do passado, tendo em conta/ considerando que representa e expõe elementos que se fizeram presente no processo de conformação do espaço.

Há de se ressaltar que, para Cosgrove, a paisagem está inserida, enquanto conceito, dentro de um campo acadêmico, servindo de ferramenta analítica, buscando 0 entendimento do mundo e das sociedades, que a produzem e compartilham, dotando-as de símbolos e informações, passadas de geração para geração. Assim, os significados atribuídos não são estáticos, variando de acordo com o tempo e com os grupos sociais que se encontram enquanto dominante ou dominado.

Complementando esse debate, Augustin Berque, geógrafo frânces, professor e diretor da École des Hautes Études en Sciences Sociales de Paris, contemporâneo aos autores da nova geografia cultural, em seus trabalhos desenvolve 0 conceito de paisagem, tratando-a como marca, na medida em que representa uma sociedade a partir de sua materialidade, sendo passível de descrição e inventario, mas também como matriz, a partir do momento em que influência na questão da percepção, concepção e ação (no que tange 0 aspecto cultural como um todo) do indivíduo, ou seja, ela é vista por um olhar, apreendida por uma consciência, 
valorizada por uma experiência, julgada e reproduzida por um padrão moral e estético, gerado por um tipo de política, etc. Conforme afirma 0 autor: a paisagem é marca, pois expressa uma civilização, mas é também uma matriz porque participa dos esquemas de percepção, de concepção e de ação - ou seja, da cultura (BERQUE, 1998; p.p. 84-85).

Para Berque (1998), a paisagem é uma abstração que não está contida exclusivamente no objeto ou no sujeito, mas sim na interação complexa entre esses elementos. Sendo assim ela possui a marca de uma cultura e também a influencia, ou seja, um processo simultâneo, a paisagem é captada por um olhar, mas também 0 determina; neste sentido se apresenta como um agente ativo, passivo e potencial. E $m$ suas palavras a paisagem e 0 sujeito são co-integrados em um conjunto unitário que se auto-produz e se auto-reproduz - e, portanto, se transforma (BERQUE, 1998; p. 86).

Nesses autores, a ação humana passa a ser ressaltada na paisagem, seja como um reflexo da mesma (com seus atos influenciados pelo local que está inserido) seja como um agente transformador (na medida em que se apropria dos recursos disponíveis, moldando-a sua maneira). Por esse prisma, a paisagem é abordada como entidade espacial que se relaciona de maneira direta e dependente com a história econômica, cultural e ideológica, tendo sua acepção variando de acordo com 0 contexto que se insere, sendo tratada como uma unidade portadora e representante das funções sociais. Nesta perspectiva, ela corrobora com os debates acerca do patrimônio industrial, pois por eles se faz possível remontar as relações que se deram em um determinado tempo, agindo como um documento de suma importância, em que sua leitura extrapola ao que está exposto ao olho nu (mas tendo-o como característica importante).

O patrimônio industrial e a paisagem cultural: a interação dos conceitos

Como aponta Choay (2003), desde sempre as inovações tecnológicas exerceram influência no cotidiano da sociedade e na formação do ambiente vivido, atribuindo-Ihes novas funções. Assim, transformações vão ocorrendo e resquícios gerados, sendo incorporados de duas maneiras distintas. $\mathrm{Na}$ primeira, edifícios antigos, construções sólidas adaptáveis a uma nova utilização são incorporadas a dinâmica vigente, recebendo novos usos e valores; na segunda situação, os restos são tratados como marcas anacrônicas, sem valor de uso, entretanto com considerável valor afetivo, pois ressalta a memória daqueles que tinham neles seu território e local de sustento. Estes resquícios, fruto do 
processo de industrialização, são carregados de signos, se apresentando como patrimônio, na medida em que evidenciam a coletividade que o construiu (JEUDY, 1990). Com isto, o patrimônio industrial constituído possui um valor que vai além do seu aspecto visível, ressaltado essencialmente pelo meio em que se insere, pela paisagem que representa, pelas relações que estabelece com o espaço e, principalmente, pelas memórias que nele está contida (ALVES, 2003). Como aponta Jeudy (1990):

Quando entramos num atelier onde estão reunidas máquinas que funcionavam há algumas dezenas de anos atrás, escutamos a explicação dada sobre 0 trabalho e a vida dos operários e assistimos a demonstrações, nos deixamos levar pela evocação dessa atmosfera imaginando os seres que lá estiveram, que partilharam um destino comum, escutamos 0 barulho das máquinas, vozes... (1990; p.49).

No mesmo sentido Choay (2003) afirma:

Que recordam então os edifícios antigos? 0 valor sagrado dos trabalhos que os homens de bem, desaparecidos e anônimos, realizaram para honrar o seu Deus, compor os seus lares, manifestar suas diferenças. Fazendo-nos ver e tocar o que viram e tocaram as gerações desaparecidas, 0 mais humilde $\operatorname{lar}(2003 ;$ p.121).

De acordo com Jeudy (1990) no Patrimônio Industrial ficam retidos valores, modos de vida, memórias correspondentes a maneira de produzir de uma sociedade. Sendo assim sua preservação é necessária, pois possibilita a apreensão de características importantes, num momento onde a mudança e a ruptura de sentido são constantes. Segundo o mesmo a cultura técnica pode então desempenhar um papel crítico nas modalidades de análise da história das sociedades (1990; p.102). Choay (2003) também ressalta essa característica do Patrimônio Industrial. Para a autora o mesmo pode ser tratado como um documento, que por sua análise se faz possível remontar características importantes de um grupo. Em suas palavras:

[0 Patrimônio Industrial] tem um valor de documento sobre uma fase da civilização industrial, documento em escala regional, que a memória fotográfica haverá de conservar, mas cuja preservação real parece ter se tornado ilusória por suas próprias dimensões, numa época 
de urbanização e de regionalização de territórios (2003; p.219)

\section{Da mesma maneira, a} paisagem se apresenta. A tualmente, enquanto objeto de estudo, não existe, a priori, como um dado da natureza (ou seja, somente em seu aspecto morfológico), mas somente em relação à sociedade que a anima. Assim, ela é tratada como uma representação, o que a torna inesgotável, pois reproduz-se, renova-se e regenera-se, assim como a coletividade que Ihe dá vida. Neste sentido, a paisagem assume caráter identitário na medida em que as sociedades recebem e percebem, constroem e reivindicam, representam e interpretam os lugares que estão inseridos. D este modo, ela é considerada uma expressão concentrada da identidade coletiva, sendo um espelho acumulador que possibilita a representação do real e a união em torno de algo comum, influenciando na formação do ser (PISÓN, 2000). Com isso, criam identidades, que se reforçam em relação a outras, sendo consideradas heranças, passíveis de preservação. Dime el paisaje que vives y te diré quien eres (PISÓN, 2000; p.227).

Dotada de sentido e ancorada sobre uma base material, a paisagem pode ser vista como uma importante fonte investigativa, principalmente no que tange aos aspectos culturais de um determinado local. Pisón (2000) afirma que ela passou a ser vista como marco de vida, pois dá suporte ao seu desenvolvimento, sendo realidades físicas individualizadas, inseridas em organizações (naturais ou culturais) dinâmicas, dotadas de próprio sentido, se fundamentando na relação direta de sua base (o aspecto estrutural), com a forma que se materializa (aspecto morfológico) e pela forma que se materializa (aspecto cultural social). $N$ as palavras do autor:

En este juego de interacciones el paisaje no aparece, pues, solo como un ente fisionómico y estético, sino que constituye un complejo vivo de formas que cristaliza, se articula, late y reposa sobre un sistema de condiciones y relaciones geográficas, susceptible de análisis cualitativo y funcional más allá de las apariencias. (...) es expresión de una civilización, tanto material como espiritual (PISÓN; 2000; p. 216).

Por ela, a memória produtiva de uma sociedade pode ser apreendida, complementando e fazendo parte dos estudos do patrimônio industrial. Para M einig (2002), a paisagem é caracterizada por ser dual, sendo resultado da observação e fruto de um processo cognitivo, mediado pelas representações do imaginário social, repleto de simbologia. Em cada período o imaginário coletivo varia e com ele a 
concepção social do natural, traduzidas em artefatos (materiais e simbólicos) que possibilitam a melhor vivência no espaço. Essas mudanças são percebidas na paisagem, pois além de ser um conceito abstrato de compreensão do meio, se apresenta também como materialidade pela qual os indivíduos enquanto seres sociais se organizam. Sendo assim, este conceito se apresenta como a melhor maneira de estudar essas transformações, pois é portador de sentido, representando tanto a variação quanto a ideologia que há por detrás (LUCHIARI, 2001).

As paisagens construídas e valorizadas expõem a estrutura social vigente e dão contorno a lugares, pois ela é a materialidade que permite a representação simbólica. Sendo assim, ela é socialmente configurada, edificada em torno de instituições sociais dominantes e ordenada pelo poder das mesmas (CASTRO, 2005). Pisón (2000) ressalta que a característica acumuladora torna a paisagem um documento que retém as particularidades de quem (ou o que) a influencia de maneira dominante e com isso é capaz de mostrar conteúdos e o modo de vida daqueles que Ihe dão forma. Por seu intermédio pode-se apreender, interpretar e ler as características produtivas de uma sociedade e toda a estrutura que foi montada para 0 seu sucesso. Por seu intermédio, pode-se mapear a cultura e o poder que a conforma, na medida em que as políticas implementadas tem por objetivo a preservação da condição social, cedendo benefícios a elite vigente, que ostenta seu poder na suntuosidade de suas construções (CORRÊA, 2003). Desta maneira, ela auxilia os estudos relativos ao patrimônio industrial, dando maior significado ao mesmo.

As paisagens que contém elementos industriais servem de documento, possibilitando a apreensão de aspectos importantes, pois agem como um testemunho e são referências, na medida em que explicita a cultura que the deu forma, expondo os símbolos, sua representatividade técnica e social. Nelas ficam plasmadas o resultado da constante transmissão de habilidades, inovações tecnológicas, modos de vida que estão em constante contato. Assim, atua como uma forma de conservação das memórias coletivas que foram sobrepostas nesse intenso intercâmbio. 0 patrimônio industrial possui qualidades que 0 ressaltam enquanto objeto de estudo. Por seu intermédio apreende-se questões importantes que compõe a sociedade, como a dominação, hierarquização, etc., estando estas representadas não somente no campo material, mas também na dimensão imaterial (DEZEN-KEMPTER，2011). Nele, o social se acha repensado e reinterpretado pela cultura técnica 
correspondente a um determinado modo de vida, não servindo apenas como um objeto de reconstituição ou de evocação, mas sim ressaltando o viés crítico, explicitando as ideologias que foram responsáveis pela sua composição.

O local de produção industrial remete a algo externo (valores, ideais, imaginário). Assim, no meio da desestruturação do espaço que se insere, ele funciona como marca, pois apresenta especificidades que são construídas pelas diversas formas que é retratado, formando um imaginário multifacetado (DEZENKEMPTER， 2010). Os resquícios materializados pelo monumento, pelos sítios ou pelas ruínas permitem a extração de informações que servem para a construção de sua história. Entretanto, mesmo tendo diferentes interpretações, 0 seu aspecto material é incontestável. $N$ ão se pode negar que ele está lá, não podendo, portanto, perdê-lo e depois encontrá-lo. 0 que pode acontecer é seu abandono e esquecimento. $\mathrm{E}$ esse é o destino das forjas, olarias e fábricas deixadas à própria sorte, que gradativamente vão se decompondo, tendendo ao desaparecimento (JEUDY, 1990).

Desenvolver um estudo tendo como base a relação destes conceitos possibilita 0 entendimento e proteção de características importantes de uma população, que imprimiu na sua maneira de produzir aspectos que retratam sua memória enquanto grupo. Nos dias de hoje, com grandes e intensas transformações, os indivíduos, conforme aponta Choay (2003), perderam a capacidade de apreenderem informações relevantes, pois sua memória é constantemente substituída e influenciada por informações enciclopédicas e limitada. Assim, deixam de lado o valor histórico do bem, preterindo seu viés histórico construído pela memória. Essa situação tem que ser revertida, pois é na memória que os indivíduos procuram abrigo e por ela se unem, agindo enquanto sujeito inserido no grupo.

Notas

* Doutorando em G eografia pelo Programa de PósGraduação em Geografia da Universidade Federal do Espírito Santo (UFES); M estre em Políticas Sociais pelo Programa de Pós Graduação em Políticas Sociais da U niversidade Estadual do Norte Fluminense (UENF); Licenciado em Geografia pelo Instituto Federal Fluminense e Bacharel em Ciências Sociais pela Universidade Estadual do Norte Fluminense. Atualmente sou Professor EBTT do Instituto Federal Fluminense, lecionando no curso de Licenciatura em G eografia.

\section{Referências bibliográficas}

ALVES, Jorge Fernandes. Património industrial, educação e investigação - a propósito da Rota do Património Industrial do Vale do Ave. In: Seminário Património Industrial no Vale do Ave: uma Rota com História, A nais do evento; G uimarães, 2003. 
BERQUE, Augustin. Paisagem-marca, paisagemmatriz: elementos da problemática para uma geografia cultural. In: CORREAA, Roberto Lobato; ROZENDAHL, Zeny (orgs). Paisagem, tempo e cultura. Rio de Janeiro: Eduerj, 1998.

BRASIL, Constituição (1988). Constituição da República Federativa do Brasil. Brasília, DF : Senado Federal, 1988.

CAST RO, Demian Garcia. Patrimônio histórico e arquitetônico como marca de qualificação da paisagem de Quissamã: identidade cultural, poder e consumo. Dissertação apresentada ao Programa de Pós Graduação em Geografia do Universidade Estadual do Rio de Janeiro, UERJ: 2005.

CHAUÍ, M arilena. Política cultural, cultura política e patrimônio histórico. In: 0 direito à memória: patrimônio histórico e cidadania; São Paulo, DPH, 1992.

CHOAY, Françoise. A Alegoria do Patrimônio. São Paulo; U NESP, 2003.

CLAVAL, Paul. A paisagem dos geógrafos. In: Paisagens, texto e identidade. Rio de Janeiro: E duerj, 2004.

CLAVAL, Paul. A geografia cultural. Florianópolis; E ditora da U F SC, 1999.

COSG ROVE, D enis. A geografia está em toda parte: Cultura e simbolismo nas paisagens humanas. In: CORRÊA, Roberto Lobato; ROZENDAHL, Zeny (orgs). Paisagem, tempo e cultura. Rio de Janeiro: Eduerj, 1998.

CORREAA, Roberto L obato. Trajetórias geográficas.
Rio de Janeiro; Bertrand Brasil, 1997.

CORRÊA, Roberto Lobato; ROZENDAHL, Zeny. Apresentando leituras sobre paisagem, tempo e cultura". In: CORRÊA, Roberto Lobato; ROZENDAHL, Zeny (orgs). Paisagem, tempo e cultura. Rio de Janeiro: E duerj, 1998.

DEZEN-KEM PTER, Eloise. Espaço fabril enquanto lugar de memória. In: Urbana. $\mathrm{N}^{\circ} 3$, ano 3, Campinas, 2010.

F ON SE CA, M aria Cecília Londres. 0 Patrimônio em processo: trajetória da política federal de preservação no Brasil. Rio de Janeiro; E ditora U F RJ, 2005.

FUnARI, Pedro Paulo Abreu e PELEGRINI, Sandra de Cássia Araújo. Patrimônio Histórico e Cultural. Rio de Janeiro; Jorge Zahar E ditora, 2009.

HARVEY, David. A Produção Capitalista do Espaço. São Paulo; A nnablume, 2005.

HOLZER, Werther. Paisagem, imaginário, identidade: alternativas para o estudo geográfico. In: CORRÊA, Roberto Lobato; ROZENDAHL, Zeny (orgs): $M$ anifestações da cultura no espaço. Rio de Janeiro: EdU ERJ, 1999.

JEUDY, Henri-Pierre. Memórias do Social. Rio de Janeiro; Editora Forense U nivesitária, 1990.

LA BLACHE, Paul Vidal. Princípios de Geografia Humana. Lisboa: Ed. E dições Cosmos, 1954.

LUCHIARI, Maria Teresa Duarte Paes. A (re) significação da paisagem no período contemporâneo. In: Paisagem, Imaginário e Espaço. Rio de Janeiro: Eduerj, 2001.

M EINIG, D onald. O olho que observa: dez visões da 
mesma cena. In: Espaço e cultura; nำ13, 2002.

MENDES, José Amado. Industrialização e Patrimonio Industrial: desenvolvimento e Cultura. Porto; Ericeira, 2006.

NAME, Leo. 0 conceito de paisagem na geografia e sua relação com o conceito de cultura. Salvador, G eoT extos, vol. 6, n. 2, dez. 2010.

PISÓN, E duardo M artínez. La protecion del paisaje. Uma Reflexión. In: Estudios sobre El paisaje; F undacion D ques de Sória, M adri, 2000.

SANT OS, Cecília Rodrigues dos. N ovas Fronteiras e Novos Pactos para o Patrimônio Cultural; In: São Paulo em Perspectiva; São Paulo, 2001.

SANT OS, M ilton. A natureza do espaço: técnica e tempo, razão e emoção; São Paulo; H U CIT E C, 1997.
SAUER, Carl Otwin. A morfologia da paisagem. In: CORREAA, Roberto Lobato; ROZENDAHL, Zeny (orgs). Paisagem, tempo e cultura. Rio de Janeiro: Eduerj, 1998.

SILVESTRE, Federico Lopez. Pensar La História del Paisaje. In: Paisaje e Historia. Madri; Abada Editores, 2009.

TEIXEIRA, Simonne. Educacion Patrimonial: Alfabetizacion Cultural para la Ciudadania. In: Estudios Pedagógicos XXXII, n²: 133 - 145, Valdivia, 2006.

TOGASHI, Henrique Fürstenau. Interpretação da paisagem: uma tarefa interdisciplinar. Cuadernos de Geografía: Revista Colombiana de G eografía; $n .0$ 18, Bogotá, 2009.

\section{INDUSTRIAL HERITAGE AS ELEMENT ON THE CULTURAL LANDSCAPE, AND THE CULTURAL LANDSCAPE CONFORMING THE INDUSTRIAL HERITAGE: A CONCEPTUAL RELATION}

ABSTRACT: INDUSTRIAL HERITAGE IS RELATED TO THE PRODUCING MODE OF A SOCIETY, CONSTITUTED OF ITS HISTORICAL, TECHNOLOGICAL, SOCIAL AND ARCHITECTONIC OR SCIENTIFIC VALUES. IT GOES BEYOND THE AESTHETIC ASPECT, OUTSTAND BY THE VISIBLE. BY ANALYSING IT IS POSSIBLE TO CONNECT THE INDUSTRIALIZATION TYPE OF A HISTORICAL PERIOD WITH THE LIFE STYLE OF THE CORRESPONDING WORKING CLASSES, AND EXPOSES THE COLLECTIVE THAT MADE IT, PERMITTING TO UNDERSTAND THE SPATIAL CONFORMATION PROCESSES IN WHICH THIS POPULATION LIVED. THIS WAY, INDUSTRIAL HERITAGE IS INTIMATELY RELATED TO THE CULTURAL LANDSCAPE. IT CAN BE UNDERSTOOD AS A PRODUCT OF APPROPRIATION AND TRANSFORMATION OF THE NATURE BY THE MAN, BEING A CLUSTER OF MEANINGS, IMPRESSED THROUGH THE LANGUAGE, SYMBOLS AND CULTURAL TRAITS OF THE SOCIAL GROUP IN QUESTION. SENSEFULL AND ANCHORED ON A MATERIAL BASE, THE LANDSCAPE PRESENTS ITSELF AS AN IMPORTANT INVESTIGATORY SOURCE, AS A CONCENTRED EXPRESSION OF COLLECTIVE IDENTITY. IS STUDY EXPOSES SOCIAL DYNAMICS ESTABLISHED OVER THE SPACE, THAT WERE CHARACTERIZED BY RELATIONS THAT WERE DEVELOPED THERE, BEING AN IMPORTANT ANALYSIS DOCUMENT. SO, THESE TWO CONCEPTS INTERACT AND TURN POSSIBLE THE DEVELOPMENT OF AN 
ANALYSIS FIELD WHEN USED TOGETHER. INDUSTRIAL HERITAGE INFLUENCES ON CULTURAL LANDSCAPE CONFORMATION, BRINGS IT TO LIFE, CHANGES ITS FEATURES AND IS ALSO COMPOSED BY THIS CONFORMATION, BEING AFFECTED BY ITS STRUCTURE. THIS WORK AIMED TO DISCUSS THE RELATION BETWEEN THESE TWO CONCEPTS, EXPOSING ELEMENTS TO THE ESTABLISHMENT OF A DEBATE.

KEYWORDS: INDUSTRIAL HERITAGE; CULTURAL LANDSCAPE; CULTURAL GEOGRAPHY; SOCIAL SCIENCES.

\section{EL PATRIMONIO INDUSTRIAL COMO ELEMENTO DEL PAISAJE CULTURAL Y EL PAISAJE CULTURAL EN CONFORMIDAD CON EL PATRIMONIO INDUSTRIAL: UNA RELACIÓN CONCEPTUAL}

RESUMEN: EL PATRIMONIO INDUSTRIAL DICE RESPETO A LOS RESQUICIOS DEL MODO DE PRODUCIR DE UNA SOCIEDAD, CONSTITUIDOS DE SU VALOR HISTÓRICO, TECNOLÓGICO, SOCIAL Y ARQUITECTÓNICO O CIENTÍFICO. EL SE VA MÁS ALLÁ DE SU ASPECTO ESTÉTICO, RESALTADO POR EL VISIBLE. SU ANÁLISIS POSIBILITA UNA CONEXIÓN ENTRE EL TIPO DE INDUSTRIALIZACIÓN DE UN PERIODO HISTÓRICO CON EL MODO DE VIDA DE LA CLASE TRABAJADORA CORRESPONDIENTE Y EVIDENCIA TAMBIÉN LA COLECTIVIDAD QUE O CONSTRUYÓ, PERMITIENDO ENTENDER LOS PROCESOS DE CONFORMACIÓN DEL ESPACIO DONDE ESA POBLACIÓN RESIDÍA. EN ESE SENTIDO, EL PATRIMONIO INDUSTRIAL ESTÁ ÍNTIMAMENTE RELACIONADO AL PAISAJE CULTURAL, QUE PUEDE SER ENTENDIDA COMO UN PRODUCTO DE LA APROPIACIÓN Y TRANSFORMACIÓN DEL HOMBRE SOBRE LA NATURALEZA, CONSTITUYENDO UN CONJUNTO DE SIGNIFICADOS, IMPRESOS A TRAVÉS DEL LENGUAJE, DE LOS SÍMBOLOS Y TRAZOS CULTURALES DEL GRUPO SOCIAL EN CUESTIÓN. DOTADA DE SENTIDO Y ANCORADA SOBRE UNA BASE MATERIAL, EL PAISAJE SE PRESENTA COMO UNA IMPORTANTE FUENTE INVESTIGATIVA, SIENDO VISTA COMO UNA EXPRESIÓN CONCENTRADA DE LA IDENTIDAD COLECTIVA. SU ESTUDIO EXPONE LAS DINÁMICAS SOCIALES QUE SE ESTABLECIERON SORBE EL ESPACIO, QUE FUERAN CARACTERIZADAS A PARTIR DE LAS RELACIONES QUE ALLÍ SE DESARROLLARON, SIENDO ENTONCES UN IMPORTANTE DOCUMENTO DE ANÁLISIS. ASÍ, ESTOS DOS CONCEPTOS INTERACTÚAN Y LA UTILIZACIÓN DE ELLOS EN CONJUNTO POSIBILITA EL DESARROLLO DE UN CAMPO DE ANÁLISIS. EL PATRIMONIO INDUSTRIAL INFLUENCIA EN LA CONFORMACIÓN DEL PAISAJE CULTURAL, LE DA VIDA, ALTERA SUS CARACTERÍSTICAS Y TAMBIÉN ES COMPUESTO POR ELLA, SIENDO INFLUENCIADO POR SU ESTRUCTURACIÓN. EL PRESENTE TRABAJO BUSCÓ DEBATIR LA RELACIÓN DE ESTOS OS CONCEPTOS, EXPONIENDO ELEMENTOS PARA EL ESTABLECIMIENTO DE UN DEBATE.

PALABRAS-CLAVE: PATRIMONIO INDUSTRIAL; PAISAJE CULTURAL; GEOGRAFÍA CULTURAL; CIENCIAS SOCIALES. 